\title{
Sensitivity Analysis of Flexible Pavement Dimensioning Using AASHTO (1993) Method. Part II: Effect of Objective Variables
}

\author{
Hugo Alexander Rondón-Quintana ${ }^{1}$, Juan Gabriel Bastidas-Martínez ${ }^{2}$ and Saieth Baudilio Chaves-Pabón ${ }^{3}$ \\ ${ }^{1}$ Ph.D., Full Professor, Facultad Medio Ambiente y Rec. Naturales, Universidad Distrital Francisco José de Caldas, Colombia.
${ }^{2}$ Ph.D., Facultad de Ingeniería, Universidad Piloto de Colombia, Colombia.
${ }^{3}$ Ph.D., Facultad de Estudios a Distancia, Universidad Militar Nueva Granada, Colombia.
}

\begin{abstract}
This is the second part of a study that conducted a sensitivity analysis of design variables of the American Association of State Highway and Transportation Officials - AASHTO (1993) in order to evaluate their influence in the dimensioning of flexible pavements. Just as was mentioned in Part I, the authors of this paper have found that design variables can be classified in two groups named "objective" and "subjective". When these variables are defined by the designer, a high degree of variability may be present. The influence of subjective variables was presented in Part I. This paper (named Part II) shows the influence of objective variables (subgrade and traffic). As a general conclusion, the paper reports that thickness in the asphalt layer of a flexible pavement structure may increase approximately between 1.23 and 1.85, depending on the way in which the designer estimates objective variables. This could have an impact in structure costs that could vary between 1.13 and 1.5 times.
\end{abstract}

Keywords: sensibility analysis, AASHTO, design, flexible pavement, objective variables.

\section{INTRODUCTION}

Just as was mentioned in the Part I paper, in Colombia and in a great part of the world, one of the most used methods for dimensioning flexible pavement structures is that of the American Association of State Highway and Transportation Officials - AASHTO [1]. The paper also mentioned that when dimensioning flexible pavement structures with this methodology, some of the variables are "subjective" (defined by the designer, based on recommendations established by [1]) and others are "objective" variables (derived from studies carried out on the field and/or laboratory). Both types of variables, on multiple occasions, may lead flexible pavement structures to have a trend for presenting broad ranges of values that could allow for the resistance of loads imposed by traffic and climatic conditions. In Part I, a sensitivity analysis was carried out for each of the subjective variables with the purpose of assessing their influence in the dimensioning of flexible pavements and their initial cost. In this paper (Part II) the influence of objective variables is presented, which are namely subgrade and traffic. The subgrade is characterized through its resilient modulus $\left(E_{s u b r}\right)$. This mechanical parameter is generally obtained with the $C B R$ value through equation (1).

$$
E_{\text {subr }}=1500 \times C B R(\mathrm{psi})
$$

Equation (1) is recommended by AASHTO [1], and in the case of Colombia, it is generally used for $C B R$ of subgrades lower than $10 \%$. This equation was obtained based on the studies conducted by Heukelom and Foster [2] and Heukelom and Klomp [3] in the state of Illinois in United States. Logically, soils in Colombia have a different physical-chemical and mineral composition than those found in the state of Illinois. Because of this reason, equation (1) may lose reliability at the moment of being used in Colombia. There are multiple equations available in referenced literature that correlate $E_{\text {subr }}$ with $C B R$. Some of them are presented as follows:

$$
\begin{array}{r}
E_{\text {subr }}=5409 C B R^{0.711}(\mathrm{psi}),[4] \\
E_{\text {subr }}=14 C B R(\mathrm{MPa}), \text { for } C B R<10 \%,[5] \\
E_{\text {subr }}=10 C B R^{0.73}(\mathrm{MPa}),[6] \\
E_{\text {subr }}=17.6 C B R^{0.64}(\mathrm{MPa}), \text { for } C B R<12 \%,[7-8] \\
E_{\text {subr }}=750 \times C B R(\mathrm{psi}),[9]
\end{array}
$$

If one equation or another is chosen, flexible pavement structures will be different, given that the range of values for $E_{\text {subr }}$ is broad. On the other hand, the traffic variable $\left(W_{18}\right)$ is characterized through the number of axis equivalent to $18 \mathrm{kips}$ (8.2 tons). Equation (7) can be used for the estimation of this variable.

$$
W_{18}=N V P \times F C
$$

$N V P$ is the number of heavy vehicles that circulate on that lane and design period, and $F C$ is the truck factor. $N V P$ is determined using equation (8).

$$
N V P=T P D \times \frac{k_{1}}{100} \times \frac{k_{2}}{100} \times 365 \times \frac{(1+r)^{n}-1}{\ln (1+r)}
$$

$T P D$ is transit average daily (vehicles/day); $k_{1}$ is the percentage of heavy commercial vehicles $(\%) ; k_{2}$ is the lane factor and considers the percentage of vehicles that circulate on the roadway design lane $(\%) ; r$ is the rate of annual traffic growth $(\% / 100) ; n$ is the design period in years.

Pavement designers in Colombia, generally use damage factor values presented on Table 1 for the estimation of $F C$. On the other hand, if during the study of traffic, the number of vehicles and their mass is known, or if the designer uses as criterion, an assumption that vehicles that pass with their maximum allowable load weights, $F C$ is determined using equivalence 
factors $\left(f_{e}\right)$ presented in equations (9-12), named "fourth power laws" ( $q$ is the axis load in tons). If Table 1 or equations (9-12) are used, the $W_{18}$ may vary significantly, generating pavement structures with completely different dimensions.

$$
\begin{aligned}
& f_{e}=\left(\frac{q}{6.5}\right)^{4}, \text { for directional single axle } \\
& f_{e}=\left(\frac{q}{8.2}\right)^{4}, \text { for rear single axle } \\
& f_{e}=\left(\frac{q}{15}\right)^{4}, \text { for tandem axle } \\
& f_{e}=\left(\frac{q}{23}\right)^{4}, \text { for tridem axle }
\end{aligned}
$$

\begin{tabular}{|c|c|c|c|c|}
\hline \multirow{2}{*}{\multicolumn{2}{|c|}{ Vehicle }} & \multicolumn{2}{|c|}{ Damage facor } & \multirow{2}{*}{$\begin{array}{l}\text { Maximum load } \\
\text { (tons) }\end{array}$} \\
\hline & & [10] & [11] & \\
\hline \multirow{4}{*}{ B } & Small Bus & 0.05 & 0.05 & 16 \\
\hline & Bus & 0.40 & 0.40 & 17 \\
\hline & Bus metropolitan & 1.0 & 1.0 & 17 \\
\hline & Bus SITP & - & 2.51 & 20 \\
\hline \multirow{9}{*}{$\mathrm{C}$} & $\mathrm{C} 2 \mathrm{P}$ & 1.14 & 1.14 & 16 \\
\hline & $\mathrm{C} 2 \mathrm{G}$ & 3.44 & 2.15 & 17 \\
\hline & $\mathrm{C} 3$ & 3.76 & 3.15 & 28 \\
\hline & C2S1 & 3.37 & 3.13 & 27 \\
\hline & $\mathrm{C} 4$ & 6.73 & 6.73 & 34 \\
\hline & C3S1 & 2.22 & 2.33 & 39 \\
\hline & $\mathrm{C} 2 \mathrm{~S} 2$ & 3.42 & 2.27 & 39 \\
\hline & $\mathrm{C} 3 \mathrm{~S} 2$ & 4.40 & 4.21 & 50 \\
\hline & C3S3 & 4.72 & 5.31 & 52 \\
\hline
\end{tabular}

Table 1. Distribution of vehicles, axis and damage factors of 8.2 tons

\section{METHODOLOGY}

In Part I of the paper, subjective design variables were mainly described because those were the ones that varied in the sensitivity analysis. This paper (Part II) will describe in greater detail objective design variables, which will vary during simulations. Subjective variables will also be described briefly, which will remain constant. A more detailed description of design variables can be reviewed in [12].

\section{II.I. Objective Variables}

\section{II.I.I. Subgrade}

This study will use equations (1) and (6) in order to conduct simulations. Equation (1) was chosen because the method recommends it, and (6) was chosen because it is the one in which $E_{\text {subr }}$ will vary in greatest proportion with relation to (1). $C B R$ values taken from the subgrade were $3 \%$ and $10 \%$. Values lower than $3 \%$ were not chosen, given that this would require an improving of the subgrade. Using equation (1) the magnitudes of $E_{\text {subr }}$ are 4500 psi and 15000 psi, for a $C B R$ of $3 \%$ and $10 \%$, respectively. Now, although these magnitudes were chosen with equation (6) the magnitudes of $E_{\text {subr }}$ are of $2250 \mathrm{psi}$ and 7500 psi, respectively. In sensitivity analysis, the two first magnitudes of $E_{\text {subr }}$ are named $S_{1}$ and the last two are named $S_{2}$.

\section{II.I.II. Traffic}

The following traffic variable values were chosen in order to conduct simulations: $W_{18}=5 \times 10^{5}, 5 \times 10^{6}$ y $2 \times 10^{7}$. These are the same that were used in Part I of this study. These values were defined assuming that the $F C$ value was obtained using maximum values of the damage factor presented in Table 1. However, if $F C$ is obtained using equations (9-12) and assuming that vehicles pass by with maximum weight allowed in load, the $W_{18}$ could increase in approximately 2.38 times (see Table 2). In other words, during pavement design, the previous magnitudes of $W_{18}$ could increase up to $1.19 \times 10^{5}, 1.19 \times 10^{6}$ and $4.76 \times 10^{7}$, respectively, if designers use as criterion calculating $F C$ assuming that vehicles pass with maximum weights allowed. In sensitivity analysis, the first three magnitudes of $W_{18}$ will be named $N$ and the last three will be named $N_{\max }$.

Table 2. Calculating the average increases of $F C$, determining them according to Table 1 and equations (9-12)

\begin{tabular}{|l|c|c|c|c|c|c|c|c|c|}
\hline \multicolumn{1}{|c|}{ Vehicle } & B & C2P & C2G & C3 & C2S1 & C3S1 & C2S2 & C3S2 & C3S3 \\
\hline Maximum value Table 1 & 1.00 & 1.14 & 3.44 & 3.76 & 3.37 & 2.33 & 3.42 & 4.40 & 5.31 \\
\hline Equations (9-12) & 3.96 & 3.59 & 3.96 & 5.35 & 6.83 & 8.59 & 8.59 & 9.98 & 6.54 \\
\hline Increment & 3.96 & 3.15 & 1.15 & 1.42 & 2.03 & 3.69 & 2.51 & 2.27 & 1.23 \\
\hline Average & \multicolumn{6}{|c|}{$\mathbf{2 . 3 8}$} \\
\hline
\end{tabular}

\section{II.II. Subjective variables}

This type of variables was described in Part I of this paper. With the purpose of evaluating the influence of objective variables in Par II of this study, in order to conduct simulations of subjective variables, these were kept as fixed and constant. Values described in the Part I of this paper for the case of the average condition $(\mathrm{P})$ were chosen (values that are generally used by designers in flexible pavements): $P_{f}=2.5, R=90 \%, m_{2}=$ $m_{3}=0.9$. Resilient modulus values $E_{1}$ of the asphaltic concrete for the three analyzed average middle temperatures (TMAP) are shown in Table 3, and the process of obtaining them is described in the Paper Part I.

Table 3. $E_{1}$ Values in simulations

\begin{tabular}{|c|c|c|c|}
\hline $\boldsymbol{T M A P}\left({ }^{\circ} \mathbf{C}\right)$ & 10 & 20 & 30 \\
\hline $\boldsymbol{E}_{\mathbf{1}}(\mathbf{p s i})$ & $7.42 \times 10^{5}$ & $4.0 \times 10^{5}$ & $2.18 \times 10^{5}$ \\
\hline
\end{tabular}

\section{II.III. Simulations}

As control or reference simulation, we used the one in which the subgrade was characterized by using equation (1) and $W_{18}$ 
was estimated using Table 1 . This combination was named $S_{1^{-}}$ $N$. Then, simulations were performed as follows:

- The subgrade was estimated using equation (1) and the $W_{18}$ was estimated assuming that vehicles circulated with maximum weight allowed in loads $\left(S_{1}-N_{\max }\right)$.

- The subgrade was estimated using equation (6) and the $W_{18}$ was estimated using Table $1\left(S_{2}-N\right)$.

- The subgrade was estimated using equation (6) and the $W_{18}$ was estimated assuming that vehicles circulated with maximum weights allowed in loads $\left(S_{2}-N_{\max }\right)$.

\section{II.IV. Costs Analysis}

Just as in Part I of this study, once the sensitivity analysis was carried out, cost per $\mathrm{m}^{2}$ was estimated for each of the dimensioned structure. This analysis only considered cost of materials (including transport, extension, compaction, labor force and equipment). Reference unit prices for estimations were those recommended by Instituto de Desarrollo Urbano IDU [13]. Dollar price is for February of 2020.

\section{RESULTS OF SIMULATIONS}

Results of simulations are presented in Figures $1-4 . h_{1}$ refers to thickness in the asphalt layer. With the purpose of evaluating results for figures, base thicknesses $\left(h_{2}\right)$ and subbase thicknesses $\left(h_{3}\right)$ were kept constant for each analyzed temperature, depending on the subgrade's magnitude and the traffic variable (see Table 4). It is possible to notoriously observe within these figures, an increase of $h_{1}$ when there is an increase of TMAP and $W_{18}$, and a decrease in the subgrade's $C B R$. It is interesting to observe that when graphing results in the order of $S_{1}-N, S_{1}-N_{\max }, S_{2}-N$ y $S_{2}-N_{\max }$ thicknesses of the asphalt layer $h_{1}$ and the cost of structures increase in a linear manner, which presents the following trend:

- In the process of designing flexible pavements, using equation (6) in order to determine the subgrade's modulus generates a greater change in $h_{1}$ in comparison to assuming that vehicles circulate with maximum allowed weight loads.

- For any TMAP, $W_{18}$ and $C B R$ of the evaluated subgrade, assuming that vehicles circulate with maximum allowed load weights generates an approximate increase in $h_{1}$ of $25.8 \% \pm 2.7 \%$ with regard to the condition in which the $W_{18}$ is estimated based on Table 1. This entails an approximate increase of $14.6 \% \pm 2.1 \%$ in the structure's initial cost.

- For any TMAP, $W_{18}$ and $C B R$ of the assessed subgrade, uses equation (6) in order to determine the subgrade's modulus, generates an approximate increase of $h_{1}$ of $50.2 \% \pm 3.7 \%$ with relation to the condition in which the modulus is obtained with equation (1) recommended by AASHTO [1]. This entails an approximate increase of $28.4 \% \pm 3.6 \%$ in the structure's initial cost.

- For any TMAP, $W_{18}$ and $C B R$ of an evaluated subgrade, using equation (6) in order to determine its modulus and assuming that vehicles circulate with maximum weights allowed in loads generates an approximate increase of $h_{1}$ of $80.3 \% \pm 4.9 \%$ with relation to the condition in which the modulus is obtained with equation (1) recommended by [1] and the $W_{18}$

is estimated based on Table 1. This entails an approximate increase of $45.5 \% \pm 5.8 \%$ in the structure's initial cost.

Table 4. Values for $h_{2}$ and $h_{3}$

\begin{tabular}{|c|c|c|c|c|c|c|}
\hline \multirow{2}{*}{$\begin{array}{c}\boldsymbol{C} B \boldsymbol{6} \\
(\boldsymbol{\%})\end{array}$} & \multicolumn{2}{|c|}{$\mathbf{5 x 1 0}^{\mathbf{5}}$} & \multicolumn{2}{c|}{$\mathbf{5 x 1 0}_{\mathbf{1 8}}$} & \multicolumn{2}{|c|}{$\mathbf{2 x 1 0}^{\mathbf{7}}$} \\
\cline { 2 - 7 } & $\begin{array}{c}\boldsymbol{h}_{\mathbf{2}} \\
(\mathbf{c m})\end{array}$ & $\begin{array}{c}\boldsymbol{h}_{\mathbf{3}} \\
(\mathbf{c m})\end{array}$ & $\begin{array}{c}\boldsymbol{h}_{2} \\
(\mathbf{c m})\end{array}$ & $\begin{array}{c}\boldsymbol{h}_{3} \\
(\mathbf{c m})\end{array}$ & $\begin{array}{c}\boldsymbol{h}_{2} \\
(\mathbf{c m})\end{array}$ & $\begin{array}{c}\boldsymbol{h}_{\mathbf{3}} \\
(\mathbf{c m})\end{array}$ \\
\hline 3 & 15 & 30 & 20 & 40 & 30 & 50 \\
\hline 10 & 10 & 10 & 15 & 20 & 15 & 30 \\
\hline
\end{tabular}

a)

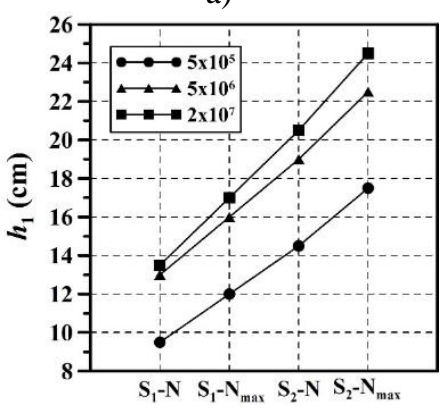

b)

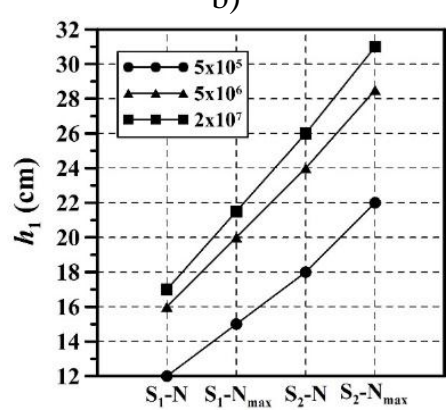

c)

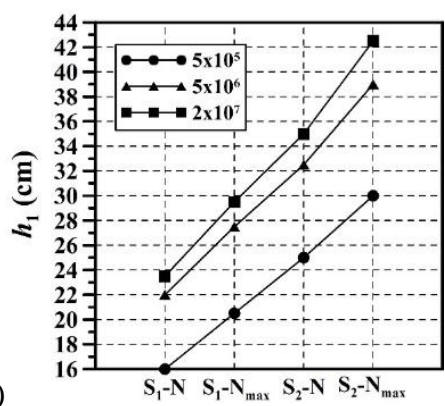

Fig. 1. $h_{1}$ for $C B R=3 \%$ and $T M A P$ of a) $10^{\circ} \mathrm{C}$; b) $20^{\circ} \mathrm{C}$; c) $30^{\circ} \mathrm{C}$

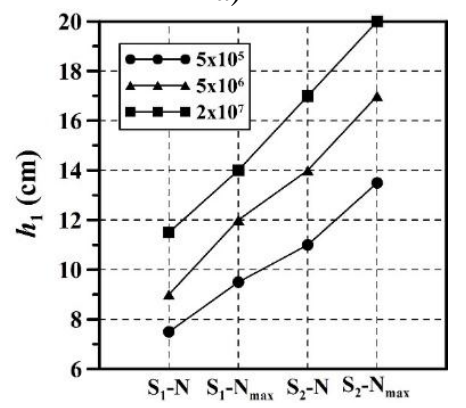

b)

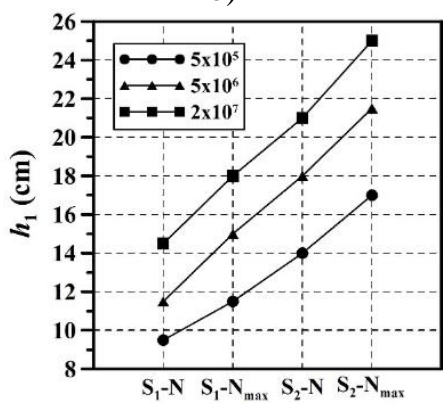

c)

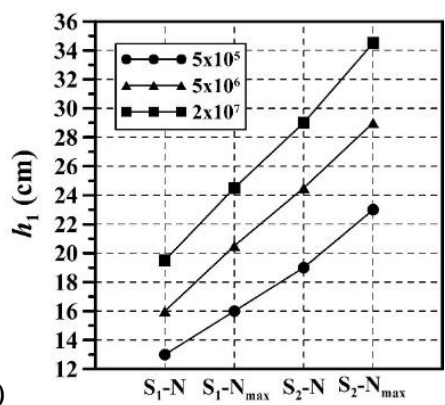

Fig. 2. $h_{1}$ for $C B R=10 \%$ and $T M A P$ of a) $10^{\circ} \mathrm{C}$; b) $20^{\circ} \mathrm{C}$; c) $30^{\circ} \mathrm{C}$ 
a)

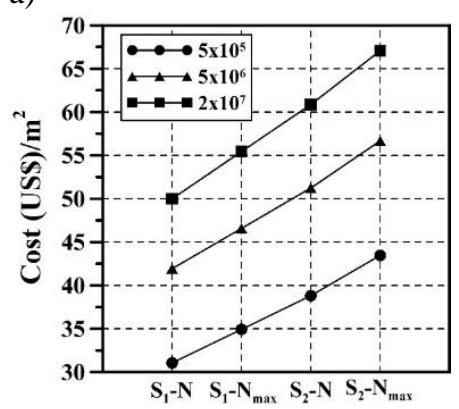

b)

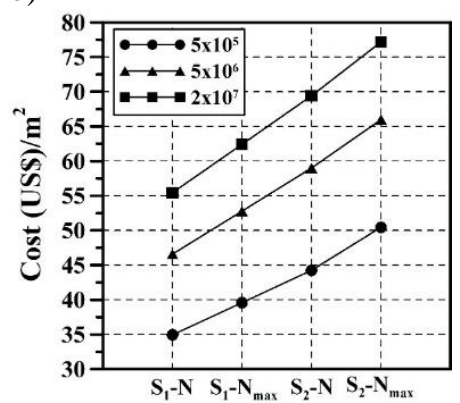

c)

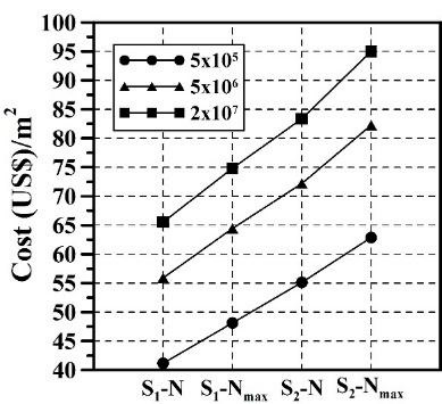

Fig. 3. Cost associated for $C B R=3 \%$ and $T M A P$ of a) $10^{\circ} \mathrm{C}$; b) $20^{\circ} \mathrm{C}$; c) $30^{\circ} \mathrm{C}$

a)

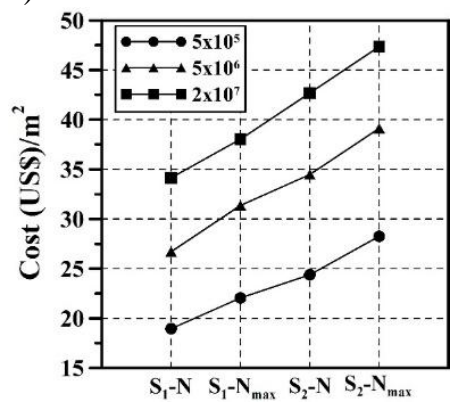

b)

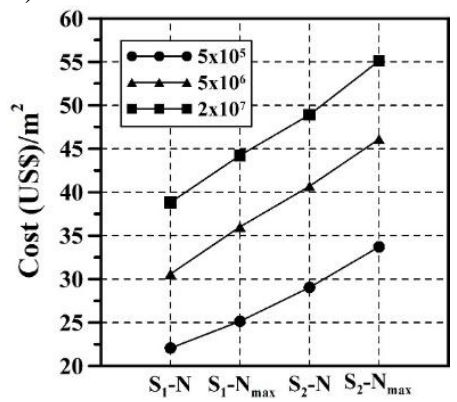

c)

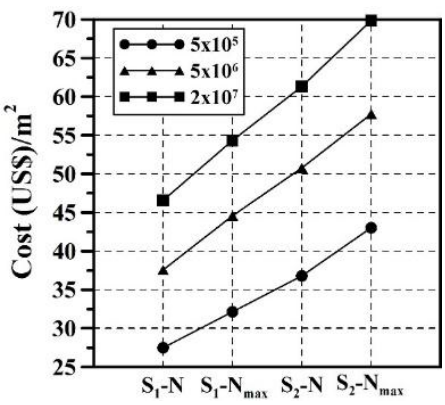

Fig. 4. Cost associated for $C B R=10 \%$ and $T M A P$ of a) $10^{\circ} \mathrm{C}$; b) $20^{\circ} \mathrm{C}$; c) $30^{\circ} \mathrm{C}$.

\section{CONCLUSIONS}

This study conducted a sensitivity analysis of each of the "objective" variables of the AASHTO [1] method, with the purpose of evaluating their influence in the dimensioning of flexible pavements and their initial cost. The following were the main conclusions obtained:
- Thickness of the asphalt layer in simulations increases in a logical manner when there is an increase of TMAP and $W_{18}$, and a decrease of the subgrade's $C B R$.

- In Colombia, when the traffic variable's $F C$ is estimated, there is a pondered average estimated from the values recommended in Table 1. However, on some occasions, designers may assume that vehicles circulate with maximum weights allowed in loads. If equations (9-12) are used for such purpose, the thickness of the asphalt layer may increase between 1.23 and 1.29 times with relation to the one obtained using the values recommended in Table 1, impacting in a cost increase for structures that vary between 1.13 and 1.17 times.

- In Colombia, in the process of dimensioning flexible pavements, equation (1) is generally used in order to determine resilient modulus. However, this equation leads to the establishment of high modulus magnitudes in comparison to others existing in reviewed literature, and when using it, it assumes that Colombian soils are similar to those found in the state of Illinois, United States. If another equation such as (6) is used, the thickness of the asphalt layer may increase between 1.46 and 1.54 times with relation to the one obtained using equation (1), impacting in an increase of structure cost that vary between 1.25 and 1.23 times.

- However, if a designer uses equation (6) in order to determine resilient modulus and assumes that vehicles that circulate on the roadway use maximum weights allowed in load, the thickness of the asphalt layer may increase between 1.75 and 1.85 times with relation to the traditional method of dimensioning, impacting in an increase for structure cost that vary between 1.40 and 1.50 times.

\section{Acknowledgements}

The authors thank the Universities related to the development of this study: U. Distrital Francisco José de Caldas, U. Piloto de Colombia and U. Militar Nueva Granada.

\section{REFERENCES}

[1] AASHTO. AASHTO guide for design of pavement structures. American Association of State Highway and Transportation Officials, 1993, Washington, DC.

[2] Heukelom, W, and Foster, C R, Dynamic testing of pavements, Journal of the Soil Mechanics and Foundations Division, ASCE, 86(SM1), 1960, 1-28.

[3] Heukelom, W, and Klomp, A J G, Dynamic testing as a means of controlling pavements during and after construction. Proceeding of 1st International Conference on Structural Design of Asphalt Pavements, 1962.

[4] Green, J L, and Hall, J W, Nondestructive vibratory testing of airport pavements. Report No. FAA-RD-73205, Vol. 1, NTIS, 1975, Washington, DC.

[5] Uzan, J, Ishai, I, Hoffman, M, Wiseman, G, and Livneh, M, Application of elasticity models for evaluation of flexible pavements. Technion, Israel Institute of Technology, Transportation Research Institute, Research Report No. 77-2, 1977. 
[6] Poulsen, J, and Stubstad, R N, Laboratory Testing of Cohesive Subgrades. Results and implications relative to structural pavement design and distress models. Methods and equipment used for nondestructive testing of materials and structures, VI internal note 106, 1980.

[7] Lister, N W, and Powell, D, Design practices for pavements in the United Kingdom, Proceeding 6th International Conference on the Structural Design of Asphalt Pavements, 1987, Ann Arbor, Michigan.

[8] Powell, W D, Potter, J F, Mayhew, H C, and Nunn, M $\mathrm{E}$, The structural design of bituminous roads. Transportation and Road Research Laboratory, Report No. 1132, 1984.

[9] Reyes, F A, Diseño racional de pavimentos. Fist Edition, Bogotá: Escuela Colombiana de Ingeniería, 2003.

[10] Murgueitio, A, Benavides, C, and Solano, E, Estudio de los Factores Daño de los Vehículos que Circulan por las Carreteras Colombianas, XI Simposio Colombiano sobre Ingeniería de Pavimentos, Cartagena, 332-342. 1997.

[11] INVIAS - Instituto Nacional de Vías, Guía Metodológica para el Diseño de Obras de Rehabilitación de Pavimentos Asfálticos de Carreteras, 2008, Bogota, Colombia.

[12] Rondón, H A, and Reyes, F A. Pavimentos: Materiales, Construcción y Diseño [Pavements: Materials, Construction and Design], Ed. ECOE, First Edition, Bogotá D.C., Colombia, 2015, 624 p.

[13] IDU - Instituto de Desarrollo Urbano. Precios Unitarios de Referencia 2019-II + Mano de Obra 2020. Disponible en:

https://www.idu.gov.co/page/siipviales/economico/port afolio. Consultado el 3 de febrero de 2020. 